\title{
The use of medicinal ozone in the treatment of maxillary bone necrosis medications related (MRNOJ)
}

\section{Soares.AL; ;Bortolotti.C2;Gil.DG ${ }^{3}$;Gadelha, $\mathrm{ME}^{4}$;Teixeira, $\mathrm{CH}^{5}$.}

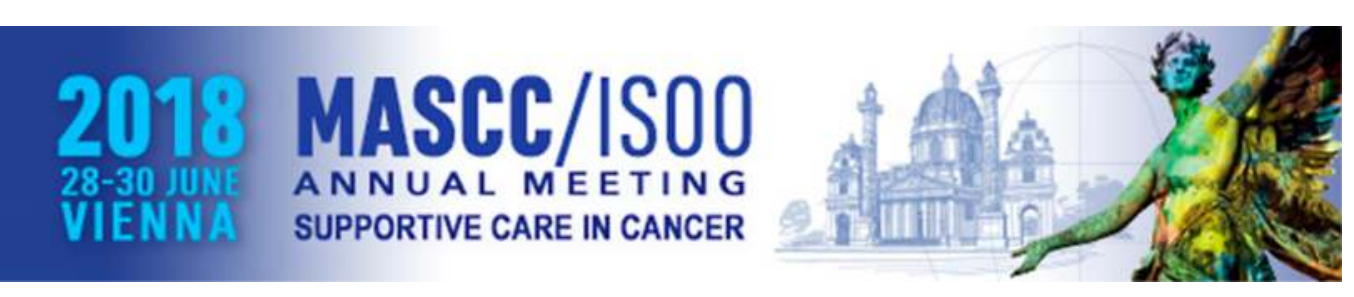

1-3 Dentistry - Oral Medicine Department from Oswaldo Cruz Hospital Sao Paulo Brazil

4-Ozone reseacher from Alpha Group

5-Oncologist from Oswaldo Cruz Hospital Sao Paulo Brazil

\section{Introduction}

Bone necrosis related to medication has been reported since 2003. It is a side effect that most often interferes negatively in the patient's quality of life because it is painful and resistant to conventional treatments. Medicinal Ozone has been used since the First World War for treatment of gangrene. In dentistry it has been used in some specialties

\section{Objectives}

The purpose of this study was to use Ozone to treat MRONJ in Osteoporotic and oncological patients and check the results in two cases wich did not reponse to convencional treatment.

\section{Methods}

82 years old osteoporotic woman on denosumab use and 64 years old man with metastatic prostate cancer for bone in monthly zoledronic acid use diagnosed with MRNOJ pos dental extractions in mandible and maxilla respectively. Both had pain, local suppuration, fetid odor, impaired oral feeding. We started approaching with ozonated water and applying ozonated medical gas before the surgical procedure. Performed surgical procedure for removal of compromised bone. In the transurgical we use ozonated water and post sutures infiltration of ozone gas.During 4 weeks we performed gas and water ozonated into the local site surgery.

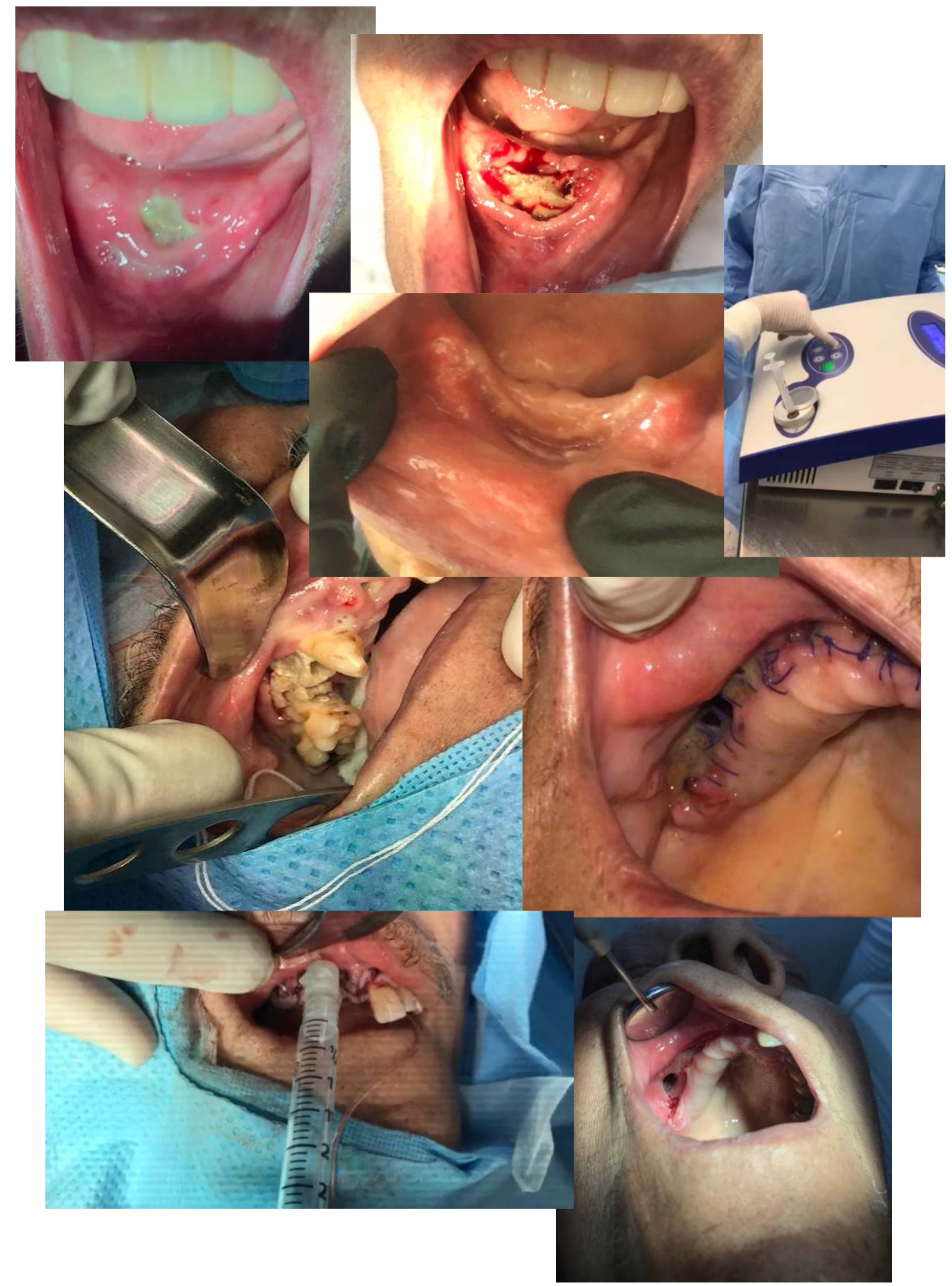

Results

In the postoperative period of 16 hours the patients no longer reported more pain, they did not show any more odor. Healing was monitored weekly in conjunction with ozonated gas and water application sessions and the success of MRONJ treatment was total.

\section{Conclusions}

The results found in the literature together with these cases are encouraging, more research are needed. 